\title{
CUADERNA
}

\section{LOS PINOS: VIVENCIA, DRAMAS SOCIALES Y CONSTRUCCIÓN DE SENTIDO. APROXIMACIÓN A UN TERRITORIO POPULAR URBANO DESDE LA ANTROPOLOGÍA DE LA EXPERIENCIA ${ }^{1}$}

\section{Teresa Ontiveros Acosta}

Antropóloga. Doctora en Sociología, Universidad de París VII. Docente-Investigadora, Asociada, Escuela de Antropología, Departamento de Etnología y Antropología Social, Facultad de Ciencias Económicas y Sociales, Universidad Central de Venezuela. Investigadora Nivel II del Sistema de Promoción del Investigador. Primer lugar del Premio Nacional de Investigación en Vivienda 1994 (premio colectivo) y Segundo lugar del Premio Nacional de Vivienda 2003. teresaontiveros@gmail.com
1- Este artículo es un producto de la investigación: Experiencia de vida social y construcción de sentido en un territorio popular urbano. Caso barrio Lo Pinos. Hoyo de la Puerta. Área Metropolitana de Caracas. Financiado por el Consejo de Desarrollo Científico y Humanístico ( $\mathrm{CDCH}$ ). Universidad Central de Venezuc versidad Central de Venezuela. Caracas. Venezuela. 2010. Agradecemos al CDCH su apoyo financiero para el desarrollo de este proyecto. 


\title{
Artículos Arbitrados
}

CUADERNO URBANO. Espacio, Cultura, Sociedad - VOL. 9 - № 9 (Octubre 2010) pp. 734. ISNN 1666-6186

\begin{abstract}
Resumen
Con base en el estudio de la vivencia y su circulación a partir de las narrativas locales, abordadas desde la relación entre experiencia y etnografía, miembros del barrio Los Pinos nos develan los dramas sociales que se han suscitado en su comunidad desde sus propia fundación. Marcados por el desalojo, la inestabilidad de los terrenos y la reubicación, han sobrevivido muy especialmente a las fases de quiebre y crisis que se derivan del desalojo y la inestabilidad geológica, pero la reubicación que se comenzó a dar en el barrio desde el año 2006 ha producido una ruptura y crisis de sentido entre sus miembros. Es así como nuestro estudio gira en torno a los procesos de exclusión y las paradojas de la inclusión en este territorio popular urbano.
\end{abstract}

\section{Palabras clave}

Barrio, vivencia, drama social, exclusión, inclusión.

\begin{abstract}
Based on the study of lived experiences and their dissemination through local narratives interpreted through the relationship between experience and ethnography, the people of the Los Pinos neighborhood reveal the social dramas that have been raised in their community since its foundation. Scarred by eviction, the land's instability and relocation, the have survived especially through phases of breakdown and crisis arising from the eviction and geological instability. But, the relocation that began to hit the neighborhood since 2006, has produced a rupture and crisis of meaning between its members. Our study focuses on the processes of exclusion and the paradoxes of inclusion within this low income urban area.
\end{abstract}

Keywords

Neighborhood, experience, social drama, exclusion, inclusion. 
Teresa Ontiveros Acosta

\begin{abstract}
LOS PINOS: VIVENCIA, DRAMAS SOCIALES Y CONSTRUCCIÓN DE SENTIDO. APROXIMACIÓN A UN TERRITORIO POPULAR URBANO DESDE LA ANTROPOLOGÍA DE LA EXPERIENCIA
\end{abstract}

\title{
1. INTRODUCCIÓN
}

A finales del año 2006 propusimos ante el Consejo de Desarrollo Científico y Humanístico, Universidad Central de Venezuela, el proyecto titulado Experiencia de vida social y construcción de sentidoenun territorio popular urbano. Caso barrio Los Pinos. Hoyo de la Puerta. Área Metropolitana de Caracas. Con este estudio intentábamos seguir indagando en una realidad popular, la cual nos abrió sus puertas, metafóricamente hablando, en el año 2003. Después de un año dedicados al proyecto, elaboramos un informe con el título: "Esto es lo único que tengo". Amenazas de desplazamientos forzados de población y mecanismos de resistencia. Caso Barrio Los Pinos. Hoyo de la Puerta, Municipio Baruta. Área Metropolitana de Caracas (Ontiveros

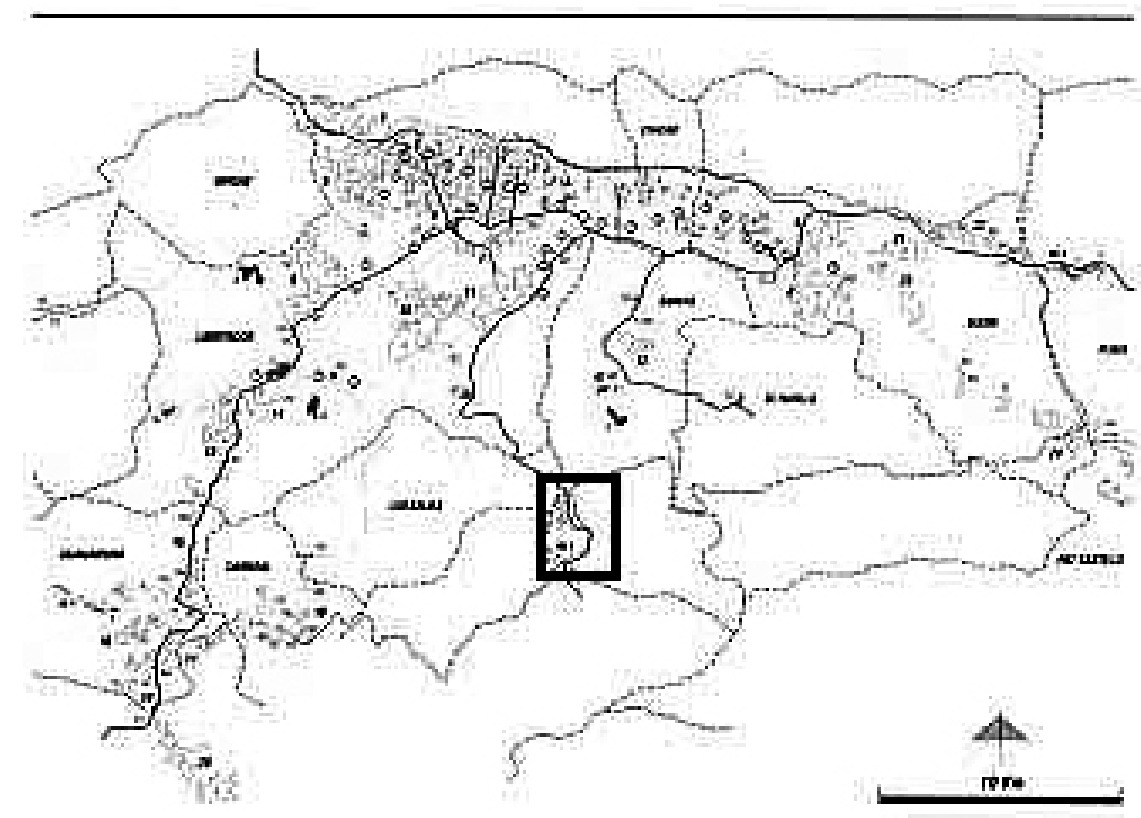

1- Ubicación del Sector Hoyo de la Puerta en el Área Metropolitana de Caracas (AMC). El cuadrado indica zona de estudio donde se localiza el barrio Los Pinos 


\section{Artículos Arbitrados}

CUADERNO URBANO. Espacio, Cultura, Sociedad - VOL. 9 - № 9 (Octubre 2010) pp. 734. ISNN 1666-6186

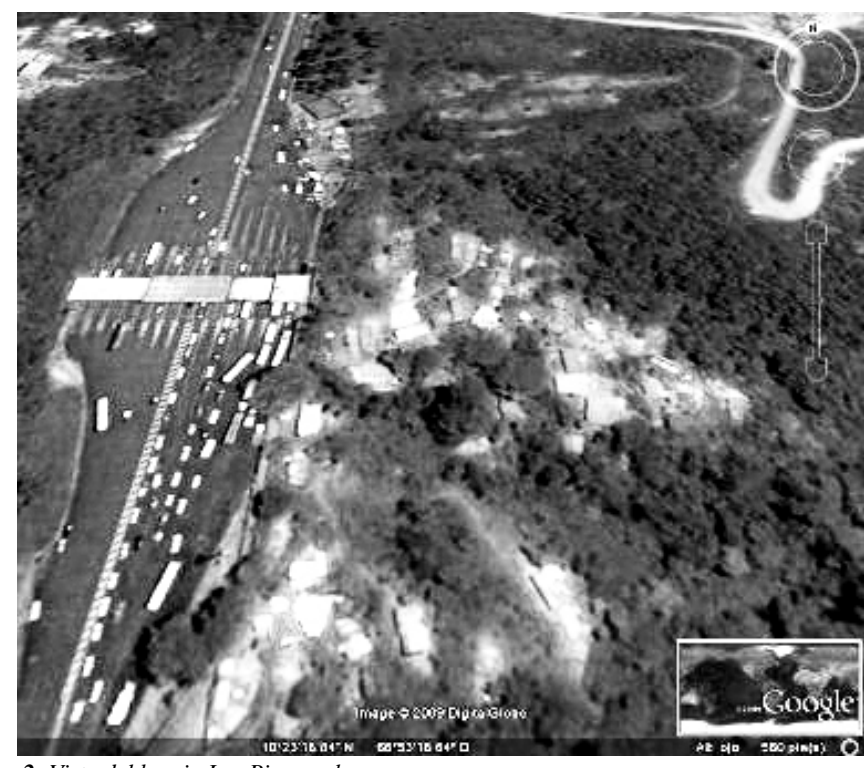

2: Vista del barrio Los Pinos, a la derecha, en forma de triángulo

3 y 4: Vista del Barrio Los Pinos. Foto: T. Ontiveros. 2009 y GutiÉRREZ, 2004). Este título conjugaba la situación vivida por la comunidad; dicha frase expresión de una de las entrevistadas manifestaba cómo ante un proceso inminente de desalojo, el admitir encontrarse en un terreno considerado inestable y estar asentados en terrenos aparentemente de propiedad privada, el aferrarse al hogar, al pedazo de tierra construido, les permitía un "estar y viviren la ciudad".

Una descripción desde fuera del barrio Los Pinos nos arrojaría las siguientes características: está ubicado al suroeste de la ciudad de Caracas, en el sector Hoyo de la Puerta (imagen 1).

Se encuentra emplazado en una topografía montañosa con fuertes pendientes de dirección oeste-este, muestra una forma triangular configurada por los drenajes naturales existentes, con una superficie de 3,28 ha, aproximadamente, estando su parte más alta a 1175 msnm y su parte más baja a 1075 mnsm (imagen 2).
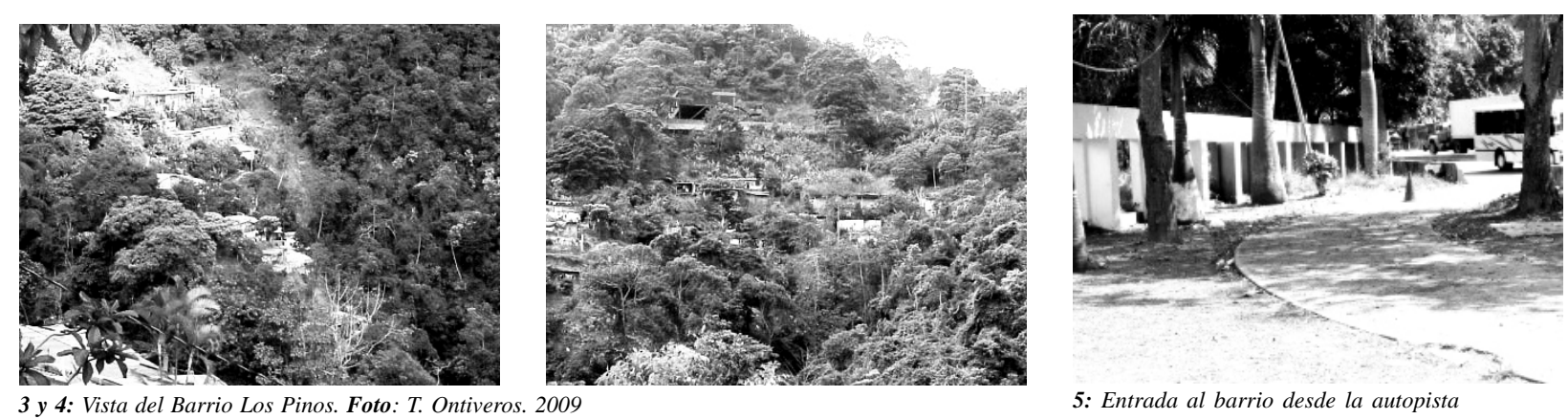

5: Entrada al barrio desde la autopista 
Teresa Ontiveros Acosta

\begin{abstract}
LOS PINOS: VIVENCIA, DRAMAS SOCIALES Y CONSTRUCCIÓN DE SENTIDO. APROXIMACIÓN A UN TERRITORIO POPULAR URBANO DESDE LA ANTROPOLOGÍA DE LA EXPERIENCIA
\end{abstract}

Presenta recorridos cortos con pendientes de $44 \%$, de régimen torrencial en la estación lluviosa. Asimismo, el sector cuenta con aguas subterráneas (manantiales). La humedad es frecuentemente alta con abundante neblina, sobre todo en las partes altas de la montaña, manteniendo una vegetación exuberante. Los terrenos ocupados por el barrio Los Pinos presentan un promedio de pendientes entre 40-60 \% en su parte alta y más de $60 \%$ en su parte baja (imágenes 3,4).

El barrio Los Pinos presenta dos accesos que sirven para cada uno de los sectores existentes (sector A y sector B), los cuales comunican la población residente con un corredor peatonal o bulevar ubicado al nivel de la autopista, que coincide con el área del peaje en el canal Este, que se dirige hacia Caracas. Es en esta área donde los residentes tienen la posibilidad de abordar las diferentes líneas de transporte que transitan por la autopista, permitiendo así a los habitantes de Los Pinos dirigirse hacia otras zonas de la ciudad capital (imagen 5).

En el barrio el único tipo de circulación es el peatonal, a través de una red de caminos de tierra y escaleras de cemento, sólo en algunos sectores, construidos por los mismos habitantes, los cuales están conectados al corredor de la entrada al barrio (imágenes 6, 7,8).

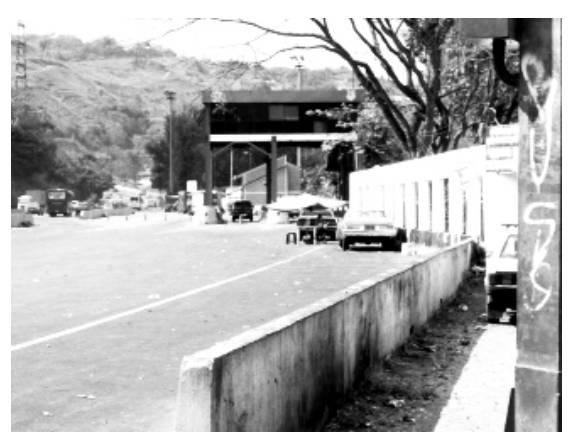

6: Autopista Regional del Centro. A la derecha queda la entrada al barrio Los Pinos. Foto: T. Ontiveros. 2009

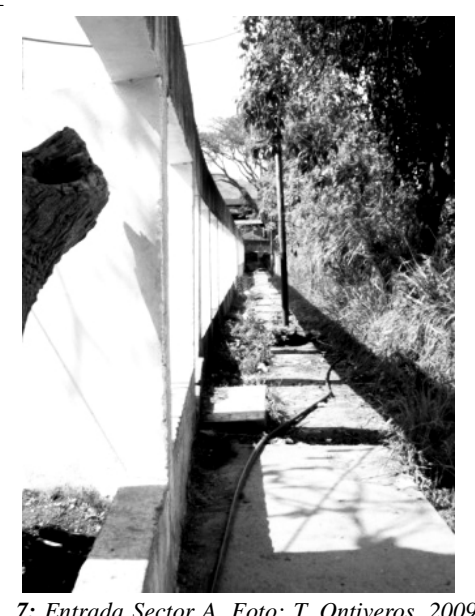

7: Entrada Sector A. Foto: T. Ontiveros. 2009

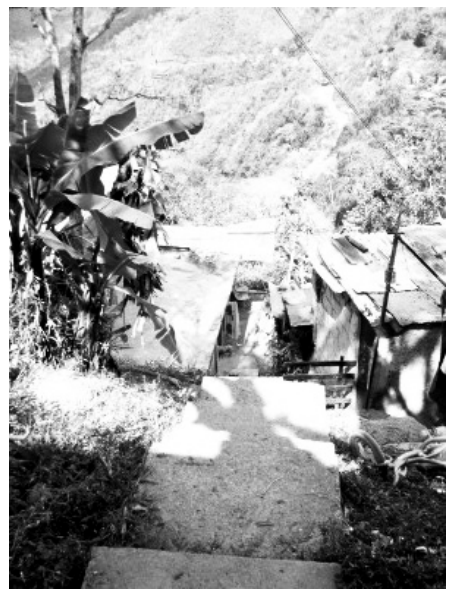

8: Entrada al Sector B de Los Pinos. Foto: T. Ontiveros. 2009 


\section{Artículos Arbitrados}

CUADERNO URBANO. Espacio, Cultura, Sociedad - VOL. 9 - № 9 (Octubre 2010) pp. 7-34. ISNN 1666-6186

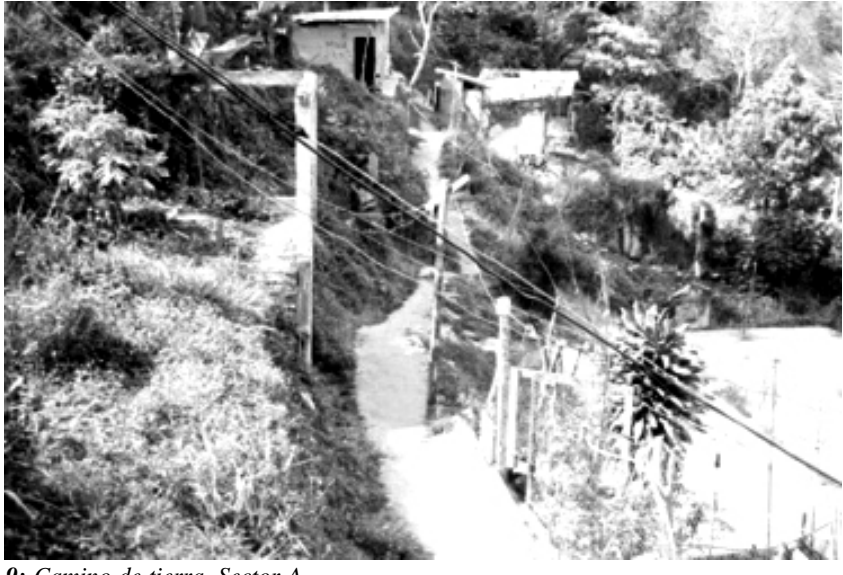

9: Camino de tierra. Sector A. Foto: T. Ontiveros. 2009
Las viviendas (imágenes 9, 10, 11, 12) han sido edificadas por sus ocupantes, quienes han acondicionado los terrenos de fuertes pendientes y construidas la mayoría de madera con techos de cinc, tipo rancho y otras de bloque, cementos para las paredes, pisos y techo (casa de barrio). Para el año 2003, según la "Asociación de Vecinos", el barrio contaba con aproximadamente 80 familias entre el sector A y B.

Producto del tiempo dedicado a la antropología de los territorios populares urbanos, no podíamos dejar de lado esta primera lectura que nos brindó la comunidad de Los Pinos. Todo ello fue originando una preocupación que se expresó en la necesidad de interrogar esta realidad popular urbana desde otra mirada: desde la experiencia de vida social y la construcción de sentido. De allí nuestra nueva propuesta de estudio.
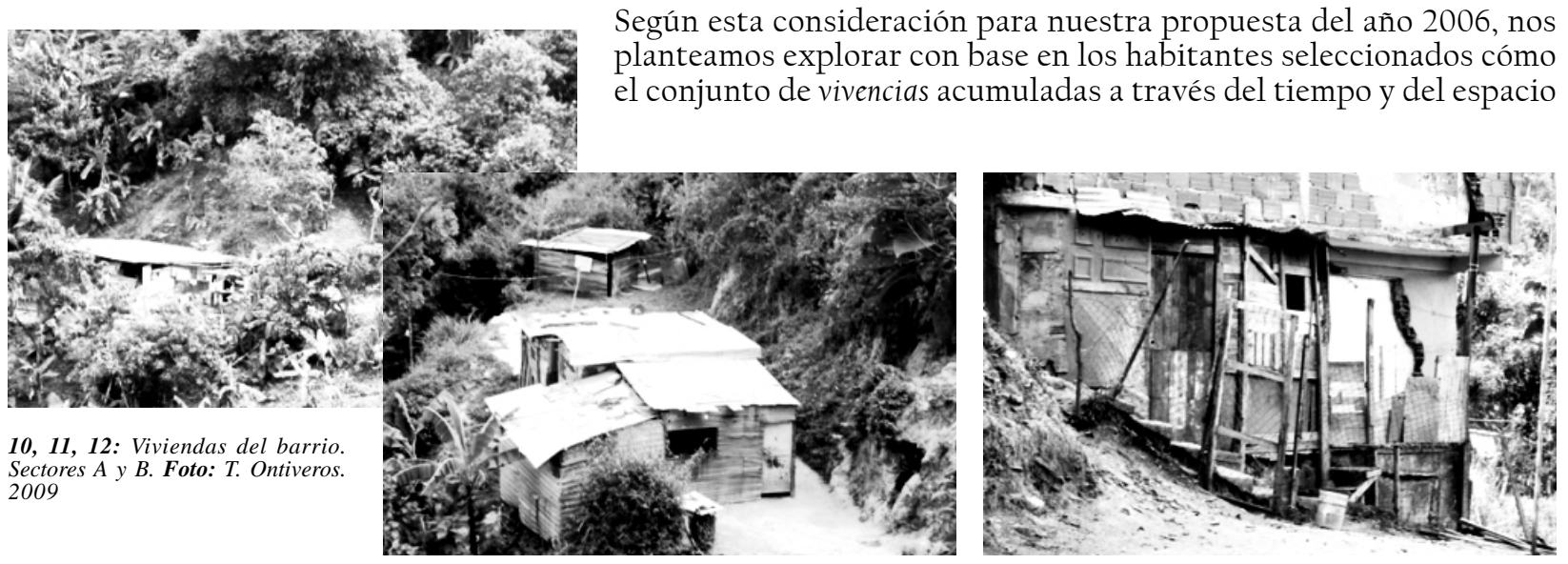
Teresa Ontiveros Acosta

\begin{abstract}
LOS PINOS: VIVENCIA, DRAMAS SOCIALES Y CONSTRUCCIÓN DE SENTIDO. APROXIMACIÓN A UN TERRITORIO POPULAR URBANO DESDE LA ANTROPOLOGÍA DE LA EXPERIENCIA
\end{abstract}

(experiencia de vida social) ha permitido una producción de sentido igualmente local, evidenciada en la percepción y significación que se le otorga a los dominios de la vida urbana.

La importancia social cobra valor en la medida en que una "interpretación de la cultura" del barrio Los Pinos desde su propia lógica de significados y experiencias de vida social nos permite resituar los alcances y limitaciones de este territorio popular urbano, con miras en coadyuvar a una mejor comprensión del mismo y de exigir las políticas públicas necesarias para el fortalecimiento de la calidad de vida del sector.

Sucintamente en este ensayo, además de algunos aspectos del referente teórico, trataremos las bases metodológicas del presente estudio, el cual merece una breve reflexión en torno a la relación experiencia y etnografía. Una etapa de análisis, la tercera en este contínuum, conforma el hueso y la carne de este estudio (expresión dilecta del antropólogo JEAN DuvignaUD). Hacemos referencia a algunos resultados de la experiencia de vida social y construcción de sentido en el barrio Los Pinos, con base en lo que nos arrojaron los datos analizados.

Para el cierre de esta introducción, queremos expresar nuestro más profundo agradecimiento a las familias del barrio por su colaboración y permitirnos con su apoyo darle forma a este estudio.

\title{
2. LA ARMADURA TEÓRICA. HACIA LA CONSTRUCCIÓN HERMENÉUTICA DE LOS DISPOSITIVOS CLAVE DE LA INVESTIGACIÓN
}

Después de varias décadas de una fuerte impronta de las teorías funcionalista y estructuralista, a partir de los años 60 y 70 del siglo pasado, nos encontramos con el irrumpir de la Antropología Simbólica e Interpretativa. Igualmente, en los 80 aparece la Antropología Postmoderna “....perspectiva que enfatiza la subjetividad de la experiencia y con ello una diferente autoridad etnográfica" (RuANo, 2000: 3, destacado nuestro).

Además de la Antropología Postmoderna surgen dos escuelas: la Antropología Crítica y la Antropología de la Experiencia, ésta desarrollada inicialmente por el antropólogo Víctor TURNER. El antropólogo mexicano Díaz Cruz considera que a partir de los 60 del siglo pasado comienza en la antropología el uso de conceptos tales como práctica, acción, situación, símbolo, significación, y destaca los trabajos del ya nombrado Víctor TuRNER y del antropólogo CLIFFORD GEERTZ. 


\section{Artículos Arbitrados}

CUADERNO URBANO. Espacio, Cultura, Sociedad - VOL. 9 - № 9 (Octubre 2010) pp. 7-34. ISNN 1666-6186

Siendo de vital importancia la propuesta del antropólogo CLIFFord GEERTz (2005), por cuestiones de espacio, nos dedicaremos solamente a dar cuenta del avance desarrollado por el antropólogo Víctor Turner, considerado el artífice y "padre" de la antropología de la experiencia. Le debemos al mismo GeERTz en 1980, cuando al discutir los usos de la metáfora del drama en las ciencias sociales y su vínculo con el concepto de experiencia, el señalar que éstas constituyen categorías centrales para comprender la contribución de Víctor Turner en el campo de la antropología (Cfr. DAWsey, 2005).

En efecto, como nos lo señala el investigador John C. DAWsEY: "En 1980, en el encuentro anual de American Anthropological Association, Victor Witter Turner, Edgard Brunery Barbara Myerhoff organizaron un simposio sobre la antropología de la experiencia. De este simposio resultaría The Anthropology of Experience (1986), con el artículo 'Dewey, Dilthey, and drama: An Essay in the Antrhropology of Experiencie', de Turner (...). Se trata de uno de sus últimos textos. Publicado tres años después de la muerte de su autor, en el mismo año de la publicación de algunos de los escritos más conocidos de la antropología 'posmoderna”' (DAWSEY, 2005: 163, traducción nuestra).

Para el estudio que desarrollamos, nos interesa el TuRnER cuya propuesta gira en torno a los dramas sociales $(1974 ; 1982)$. En su trabajo sobre el terreno entre los ndembu, TURNER observa momentos de crisis dentro de la comunidad; luego de sobrepasadas éstas, el grupo vivía procesos de reestablecimientos, los cuales generaban un mayor sentido de pertenencia entre sus miembros. La reflexión de TURNER al respecto consistió en evidenciar cómo las relaciones sociales en momentos determinados están cargadas de tensión, aspectos de la vida social que se mantienen en conflictos latentes se develan, irrumpiendo así dispositivos simbólicos profundamente arraigados, hasta el desencadenamiento de una vida social revitalizada. Los dramas sociales repercuten para dar paso a nuevas experiencias colectivas.

Los dramas sociales se expresan en formas narrativas, contenidas en fases de ruptura, crisis, reajustes y reintegración de la vida social. Es en la fase de reajuste cuando se ejercita la reflexividad. Según Díaz CRuz es la reflexividad un componente fundamental en la construcción de una antropología de la experiencia, ya que ésta constituye una “... experiencia singular que provoca el descentramiento y separación de nosotros mismos para conocernos en el mundo, para definirnos, erigirnos y transformarnos como sujetos activos a propósito del futuro pero sin desconocer algún arraigo en nuestro pasado: ahí se replantean y modifican las identidades personales y colectivas, se reinventan y resignifican las tradiciones" (DíAz CRUZ, 1997: 10). 
Teresa Ontiveros Acosta

\begin{abstract}
LOS PINOS: VIVENCIA, DRAMAS SOCIALES Y CONSTRUCCIÓN DE SENTIDO. APROXIMACIÓN A UN TERRITORIO POPULAR URBANO DESDE LA ANTROPOLOGÍA DE LA EXPERIENCIA
\end{abstract}

Con esta pequeña entrada con respecto al pensamiento de TURNER, arribamos al núcleo central de nuestro interés investigativo. Es el TURNER de sus últimos años, cuya orientación giró en torno a la propuesta filosófica de Withelm Dilthey, sustentando las bases para una antropología de la experiencia.

Disthey, filósofo alemán, estudioso de la hermenéutica, considera que un estudio desde las ciencias humanas debe tomar en cuenta tanto la experiencia personal como la reflexividad en torno a la experiencia. En este sentido, desarrolla un análisis con respecto al concepto de experiencia: Erlebnis, lo cual significa la vivencia, lo que se ha vivido. Es así como para TuRNER la experiencia vivida está constituida por varios momentos: 1) lo que acontece a nivel de la percepción; 2) las imágenes del pasado que se evocan; 3) los eventos revividos; 4) el pasado articulado al presente, dando sentido a lo socialmente construido; 5) la expresión como signo de su "completud". Y es la cultura el conjunto de estas expresiones. En este sentido, Turner reclama una ciencia humana cargada de experiencias vividas (Cfr. ReYNoso, 1998).

Reconociendo el aporte fundamental de Víctor Turner en lo que se ha denominado la Antropología de la Experiencia, queremos dar cuenta de otros estudios y contribuciones, con respecto a esta perspectiva antropológica, y hacer voces con la antropóloga LeTICIA RuANo cuando señala cómo, en el presente, "... la antropología de la experiencia ha llegado a ocupar un lugar significativo en el conjunto de los modelos antropológicos” (RUANo, 2000: 1).

Con el sugestivo título: "La vivencia en circulación. Una introducción a la antropología de la experiencia" (1997), el antropólogo Díaz Cruz, nos expone aspectos fundamentales del estudio que nos ocupa. Los dramas sociales a través de las narrativas no sólo nos dan cuenta de relatos formales, sino, en esta perspectiva de Díaz Cruz, pueden dar cuenta de los relatos no oficiales, relatos silenciados y enmascarados; igualmente a través de la fuerza de los dramas sociales se puede lograr la legitimación de los modos de existencia social.

Para Díaz Cruz, la experiencia vivida se organiza a través del lenguaje, éste como producto y como proceso histórico-cultural. Como realidad básica, la experiencia no es amorfa, ya que “... se la organiza a través de expresiones, relatos, narrativas, dramas sociales y realizaciones culturales (...) en general que se muestran y comunican, esto es, que se hacen públicas" (Díaz CrUz, 1997: 12. Subrayado nuestro). La dimensión pública de la experiencia es de vital discusión, ya que es a partir 


\section{Artículos Arbitrados}

CUADERNO URBANO. Espacio, Cultura, Sociedad - VOL. 9 - № 9 (Octubre 2010) pp. 734. ISNN 1666-6186

2- Estos últimos entendidos desde la propuesta de TURNER, como un movimiento espontáneo, "donde los significados, valores y objetivos centrales de una cultura se ven en 'acción', mientras dan forma y explican la conducta" (SCHECHNER, 2000: 16). de ésta que tiene sentido hablar de la circulación de las vivencias; como principio de interacción, podemos intercambiar saberes, historias individuales y colectivas, discursos de la existencia.

Por último Díaz CRuz se interroga: "... iqué relación existe entre los dramas sociales y la experiencia? [respondiendo] A diferencia de las 'meras' vivencias, aquéllas que sólo no requieren ser expresadas, sino que difícilmente serán expresadas, los dramas sociales están saturados de [...] 'Unas' experiencias que van configurando la propia identidad personal y colectiva: que van modificando, afinando y solidificando los contenidos asociados a la trama conceptual de la mente: intenciones, creencias, deseos, intereses, emociones y afectos..." (Díaz Cruz, 1997: 13, resaltado nuestro).

La antropóloga Leticia Ruano (2000) destaca la dimensión temporal de la experiencia “...es decir, lo que vivimos a través de ella que se constituye como auto referencia cuando es narrada" (RUANo, 2000: 5). Considera que son de interés para el antropólogo [a] de la experiencia, las expresiones y los performances. ${ }^{2}$

En lo que respecta a nuestra propia propuesta podríamos decir cómo a mediados de los años 80, a propósito de la tesis doctoral Marín. La memoria colectiva de un barrio popular de Caracas (Ontiveros, 1985), como parte de nuestra producción en cuanto a un concepto de memoria colectiva, arribamos a su definición indicando que ésta es un acto de narración en un contexto social determinado, con ello hacíamos mención a la reconstrucción de la memoria a partir del relato y la experiencia de vida social.

Si bien más adelante, en nuestro quehacer investigativo, el hablar de experiencia se hacía de manera tangencial (ONTIVEROs, 1996, 2000), no es sino en el ensayo escrito junto con el antropólogo Júlio de Freitas, con el título: "Repensando el barrio. Papel del antropólogo en la rehabilitación de los espacios autoproducidos" (1996) donde se asoma con mayor claridad una propuesta en torno a lo que considerábamos relacionado con el tema de la experiencia.

En efecto, definíamos al barrio como aquel espacio donde se produce un entretejido de red de significantes, fruto de los vínculos e intercambios entre el espacio doméstico-barrio-ciudad; en este sentido, no se puede invisibilizar al barrio, ya que éste participa del circuito urbano, aunque de una manera desigual y segregada. 
Teresa Ontiveros Acosta

\begin{abstract}
LOS PINOS: VIVENCIA, DRAMAS SOCIALES Y CONSTRUCCIÓN DE SENTIDO. APROXIMACIÓN A UN TERRITORIO POPULAR URBANO DESDE LA ANTROPOLOGÍA DE LA EXPERIENCIA
\end{abstract}

Así como se ha tratado de estereotipar al barrio en su dimensión espacial como una arquitectura del caos, asimismo por la diversidad que éste contiene, del origen de sus habitantes, de sus manifestaciones y representaciones colectivas, creencias, etc., se ha tendido a pensar en éste como el reservorio de una "cultura del caos", rebelándonos ante este juicio/prejuicio, indicábamos lo siguiente: "Es, justamente, esta diversidad lo que convierte al barrio en un espacio cuyo principal alimento es la simbiosis de experiencias societales. [...] Esta simbiosis de experiencias societales podemos observarla a partir de las diferentes 'estrategias y modos de vida' que escenifican en la trama del vivir diario los habitantes de los barrios" (Ontiveros y De FreITAS, 1996: 131).

Hoy, con esta riqueza interpretativa elaboramos una lectura de Los Pinos a través de la circulación de la vivencia, los dramas sociales advenidos en esta comunidad y cómo ello ha producido o no la construcción de sentido social.

Si la cuestión del sentido tiene que ver con "... el establecimiento de un nexo entre los sujetos sociales] y el mundo, por intermedio de valores socialmente reconocidos" (BARBIER, 1997: 4) o "... la interpretación (individual o colectiva) del significado (elaborado, suscitado, evocado) desde el contexto sociocultural, esferas de vida y lugar que se ocupa en la estructura social" (Corrales Díaz, 1997:), sería prudente preguntarnos, en una realidad concreta como lo es el barrio Los Pinos, icómo se interpreta desde el contexto del barrio, desde el lugar que se ocupa en la estructura social (pobres extremos), la vida colectiva, la identidad, los vínculos sociales?

Justamente el vínculo social para MARC Augé permite acercarnos al estudio del sentido. Más que una abstracción, el sentido es “... conciencia compartida (recíproca) del vínculo representado e instituido en el otro" (AugÉ, 2004: 99). Asimismo, AugÉ establece una relación entre los vínculos sociales (sentido) y las identidades; nos dice al respecto: “... identidades que suponen el establecimiento previo de vínculos con otros, con ciertas categorías de otros: padres, parejas, conciudadanos, colegas. Poder crear este vínculo con los otros es la condición necesaria para crear la identidad, las identidades (...) cada vez que hablamos de la 'crisis de identidad' que es consustancial a nuestrápoca, lo que planteamos es la dificultad de pensar el vínculo con los otros" (Augé, 2004: 99).

No obstante las crisis de identidades, estamos de acuerdo con Augé cuando nos indica que el vínculo simbólico no puede desaparecer, ya que en sus palabras éste es "...consustancial a la idea de lenguaje, humanidad y sociedad" (AugÉ, 2004: 102). Pudiéramos agregar, entonces, que el vínculo simbólico es igualmente consustancial a la experiencia social, ya que 


\section{Artículos Arbitrados}

CUADERNO URBANO. Espacio, Cultura, Sociedad - VOL. 9 - № 9 (Octubre 2010) pp. 734. ISNN 1666-6186

la experiencia después de este largo recorrido es, por un lado, social, comunicada y practicada, por el otro, se vive en el cuerpo individual como especificidad, pero sujetada a los hilos invisibles de los saberes culturales, de las representaciones, imaginarios y de una memoria social, que se activan cuando se pone en juego a través del intercambio en sus múltiples dimensiones la circulación de las vivencias, dando cuenta de los dramas sociales, su expresión, reflexividad y comprensión, así como de las potencialidades socioculturales de los grupos, como marcadores de identidad (individual y colectiva).

\section{EXPERIENCIA DE VIDA Y ETNOGRAFÍA}

Nuestro estudio acerca de la experiencia de vida y construcción de sentido se abordó desde el diseño cualitativo, apoyándonos en el método etnográfico (trabajo de campo) como proceso (Aguirre Cauhé, 1997), acudiendo al estudio de caso (barrio Los Pinos); por ende, hacemos referencia a un estudio microsocial, ya que nos interesamos desde la propuesta de ISAAC JOSEPH en ir de las experiencias individuales a las colectivas (y viceversa) a la puesta en escena de las relaciones sociales, intentando tejer la trama social como expresión y síntesis de una realidad compleja.

Desde el estudio de la experiencia nos encontramos igualmente con una redimensión del abordaje etnográfico. La relación interactiva que se produce entre el investigador y el informante provoca un vínculo mediado por el nos-otros, ya que, "Con la antropología de la experiencia, el antropólogo comprende la vida social como experiencia vivida por parte de él y sus interlocutores" (RuAno, 2000: 7). Para RuAno, el estudio etnográfico debe entenderse como "... una negociación constructiva que involucra por lo menos a dos o más sujetos conscientes y políticamente significantes. El uso del yo presupone un tú y el discurso se da en una situación compartida, el significado se da por la interlocución y el contexto. Esto es lo que se conoce como el modelo del diálogo" (RUANO, 2000: 8).

Son varias las herramientas etnográficas para abordar la relación investigador-informante; en nuestro caso hemos privilegiado por un lado la observación, pero nuestro análisis fue realizado con base en las entrevistas abiertas llevadas a cabo a trece jefes(as) de familia (8 mujeres y 5 hombres). Nuestro contacto con la comunidad se dio a lo largo de ocho meses (marzo-octubre de 2009), fines de semana (especialmente los sábados, en la mayoría de los casos pasábamos 7 horas en la comunidad, contabilizados los sábados hacen un total de 32 sábados consecutivos y aproximadamente 214 horas). 
Teresa Ontiveros Acosta

\begin{abstract}
LOS PINOS: VIVENCIA, DRAMAS SOCIALES Y CONSTRUCCIÓN DE SENTIDO. APROXIMACIÓN A UN TERRITORIO POPULAR URBANO DESDE LA ANTROPOLOGÍA DE LA EXPERIENCIA
\end{abstract}

Pudimos realizar un encuentro triangulado de la realidad del barrio; es decir, además de las entrevistas, hicimos recorridos por la comunidad, investigamos en por lo menos 23 instituciones aspectos concernientes a la vida del barrio Los Pinos ${ }^{3}$ (referidos a servicios y equipamientos, a la tenencia de la tierra, a escuelas y salud dentro del barrio, historia del barrio, etc., sin encontrar información relevante al respecto), asistimos a una reunión y a una fiesta colectiva - esta última en virtud de la celebración del Día de la Resistencia Índígena (12 de octubre, pero celebrada en la comunidad el 17 de octubre de 2009) - la grabación de un documental por parte de la antropóloga Isabela Luján y el comunicador social Raúl Sojo Montes, a propósito de nuestros estudios en los barrios y muy particularmente en el barrio Los Pinos.

El tiempo de las entrevistas fue variado, hubo un caso de tres horas de duración, siendo la media la entrevista de una hora; en total, sumamos 17 casetes de una hora de duración, que arrojaron un corpus aproximado de 500 páginas de texto. Se procedió a su análisis a partir de la agrupación por ejes temáticos, luego se realizó su interpretación sobre la base del análisis y construcción de las narrativas locales. A continuación, algunos de los resultados/hallazgos, tomando en cuenta sólo ciertos hitos, para la presentación de este artículo.

\title{
4. LOS DATOS Y SU EXPRESIÓN
}

\subsection{El regreso al barrio después de cinco años de ausencia}

Cuando arribamos al barrio en 2009, vimos con asombro cómo aproximadamente la mitad de las familias (40 de 80) ya no estaban allí, constatamos la situación de intensa precariedad que estaba viviendo la zona: muchas casas destruidas debido a la partida de esas familias, las caminerías mucho más deterioradas y un ambiente de soledad pasmosa. Varios de los fundadores del barrio todavía permanecían en el lugar. Con ellos tuvimos la fortuna de conversar de nuevo; a partir de ese momento, se nos presentó la preocupación de no contar con la misma población de años atrás, pero de inmediato nos surgió la idea de conversar con algunas familias que ya habían partido con la finalidad de contrastar el proceso que actualmente vivían. Fue así como realizamos diez entrevistas a las familias de Los Pinos y tres entrevistas a familias que fueron reubicadas a un "urbanismo" popular recientemente creado, llamado Ciudad Betania, el cual se encuentra en Ocumare del Tuy, Municipio Lander del estado Miranda. desde allí empieza nuestro recorrido junto con la comunidad...

3- Agradecemos a los bachille res de la Escuela de Antropolo gía Angélica Torres, Eduardo Correa, María Fernanda Salas, Naylet Bello y Rusbelly Gómez por su colaboración en la primera etapa de este proyecto; tuvie ron como tarea buscar informa con como tarea buscar informa ción institucional acerca del barrio Los Pinos. Constatamos cómo Los Pinos sigue siendo in-
visible para las instituciones del Municipio Baruta, para los programas regionales y hasta nacionales. 


\section{Artículos Arbitrados}

CUADERNO URBANO. Espacio, Cultura, Sociedad - VOL. 9 - № 9 (Octubre 2010) pp. 734. ISNN 1666-6186

4.2. Una interpretación émic de la categoría experiencia de vida social: "La experiencia para uno es sabiduría de la vivencia"

Con este título se resume una de las reflexiones aportada por una de las entrevistadas, la señora $\mathrm{O}$, quien en este momento no tiene casa fija en el barrio y vive con la ayuda de sus vecinos, especialmente los del sector B. Destaca en su opinión una característica fundamental: la experiencia es saber. Ante esta definición nos agrega: "La experiencia para uno es sabiduría de la vivencia. Que lo que uno vive adquiere la experiencia... es un aprendizaje. Uno sólo no puede aprender, siempre se mete el maestro, el padre, la madre, el todo, hasta las niñeras, todo el mundo. La experiencia sirve para uno sobrevivir, sobre todo, para uno sobrevivir en la vida. Porque si usted no tiene experiencia, no tiene astucia, no tiene precaución. Yo tengo los años que tiene esta autopista, los tengo yo cruzándola, desde que era niña" (Sra. O. Destacado nuestro).

Observamos cómo este relato hace referencia a aspectos de vital importancia: la experiencia se produce a través de la enseñanza-aprendizaje, es un intercambio de vivencias. De igual forma lo manifiesta otro de nuestros informantes: "La experiencia que uno ha tenido, que uno ha conocido, con lo que ha pasado, todo lo que uno ha vivido pues, y lo que le ha quedado de la experiencia de las vivencias que uno ha tenido" (Sr. Ro.).

Queremos destacar un aspecto fundamental: en la lógica de los entrevistados la experiencia está vinculada con la sobrevivencia, en el caso de la señora O., una sobrevivencia al día tras día en la calle. Este aspecto, el de la sobrevivencia, lo encontramos en otros de los relatos: "La experiencia es la que uno tiene para poder sobrevivir" (esposa del señor G.); "La experiencia son como aprendizajes que tiene uno y que son de suma importancia para uno, de la experiencia es que uno puede ir sobreviviendo, a causa de las experiencias que vas obteniendo cada día, porque para poder vivir es necesario la experiencia, que uno vaya adquiriendo, todo lo que le va enseñando las situaciones que pasan..." (Sr. Ra. líder natural del barrio).

Asimismo, la experiencia viene relacionada con la valoración que se adquiere como persona y la que otorga el lugar donde se reside, el hecho de aprender qué es lo que se tiene y lo que no se tiene. Con respecto a la primera, veamos el siguiente caso: "Una persona con experiencia es alguien, el que no tiene experiencia no puede pensar algo bueno... no es que uno nace con la experiencia, se va creando, la va uno, como es, adquiriendo a través del tiempo y los buenos 
Teresa Ontiveros Acosta

\begin{abstract}
LOS PINOS: VIVENCIA, DRAMAS SOCIALES Y CONSTRUCCIÓN DE SENTIDO. APROXIMACIÓN A UN TERRITORIO POPULAR URBANO DESDE LA ANTROPOLOGÍA DE LA EXPERIENCIA
\end{abstract}

consejos..."(Sr. G. Destacado nuestro). En la segunda intencionalidad de la valoración encontramos: "Bueno este... estar viviendo aquí en los Pinos es saber valorar el lugar donde tú vives, donde tú estés... Puedo tener la tranquilidad que mis hijos van a estar jugando y yo puedo dormir en un momento tranquilo, en cambio en otro lugar ino, no, nunca podría hacer eso!, nunca porque yo también he hablado con otras personas de diferentes partes de Caracas y me dicen: que no... nunca es igual la tranquilidad..." (Sra. E. Destacado nuestro). En este caso, se nos muestra la relación entre la experiencia y la circulación de la vivencia, el hablar con otras personas y constatar un don privilegiado de la comunidad, como lo es la seguridad. La tranquilidad para la entrevistada constituye un valor per se.

Otra representación en torno a la experiencia es la relación experiencia-comunidad, ello quizás sea el producto de ser fundadora del barrio: "Eso ha sido la vida de nosotros aquí por lo menos, por lo menos yo aquí me he sentido bien toda la vida porque me siento, bueno... una experiencia como si fuera nacido aquí, porque en verdad hemos estado bien aquí toda la vida, y bueno, los únicos problemas, bueno, es eso pues, estos terrenos son inestables y de eso, bueno, uno no tiene culpa, porque uno no iba a averiguar primero antes de meterse si eran estables o eran inestables, uno tenía que, bueno, si estaba en la necesidad de una vivienda tenía que meterse aquí, pues" (Sra. A, fundadora del barrio).

En este pequeño recorrido podemos visualizar cómo aspectos resaltados en nuestro análisis teórico son expresados por los habitantes de esta comunidad popular urbana, a partir de su propia lógica, pudiendo rescatar cómo la experiencia es una experiencia interpretada y practicada. Así, la experiencia está estrechamente vinculada con el intercambio de vivencias, la experiencia es un saber (enseñanza-aprendizaje), es una valoración personal y comunitaria, y enespecial está vinculada con la sobrevivencia.

\title{
4.3. La experiencia y existencia urbana de un barrio llamado Los Pinos
}

4.3.1. Relatos de una fundación

Recordando nuestro estudio anterior: Esto es lo único que tengo..., uno de los capítulos fundamentales de la investigación fue justamente el referido a los orígenes y fundación de la comunidad. En esta segunda entrada al barrio, contamos con la suerte de volver a entrevistar a la primera persona que empezó a ocupar el barrio, ya hace 23 años. Su relato se mantiene intacto en la medida en que lo que narra es justamente su experiencia de vida, marcada por el deseo de establecer un hogar para ella y sus hijos; luego, poco a poco el 


\section{Artículos Arbitrados}

CUADERNO URBANO. Espacio, Cultura, Sociedad - VOL. 9 - № 9 (Octubre 2010) pp. 7-34. ISNN 1666-6186

barrio comenzó a formarse, la prima que se vino con su familia, el hermano, la amiga y después otras personas que vieron los cimientos de una fundación. La señora A. explica que la vida del barrio ha estado marcada por etapas de intentos de desalojos, nunca le otorgaron los servicios, luego empezaron a escuchar acerca de los supuestos dueños y también de la inestabilidad de los terrenos. La señora O. y el señor Ra. son dos de los entrevistados con más antigüedad en la comunidad: 21, 19 años. Otras familias fundadoras ya no están en el barrio, han sido reubicadas, y los que tienen 14, 13, 10, 7 y la recién llegada (4 años) conocen una historia del barrio producto de la transmisión y circulación de los orígenes, marcada por el desalojo, la precariedad, pero también por el rescatar constantemente que es un barrio sano, tranquilo, el cual concede una paz que veremos no tiene límites.

Pero queremos resaltar un hecho para nosotros fundamental y que nos conmovió en nuestras visitas a la comunidad. Cuando finalizamos nuestro primer trabajo, hicimos entrega formal al señor Ra., como líder natural del barrio, de un ejemplar de los resultados del trabajo y es este material, nos comenta el señor Ra., el que lo acompaña a cualquier lado donde va, es el testigo fiel de los años que tienen viviendo en el barrio. En éste se encuentran fechas, comentarios sobre los títulos supletorios que poseían los habitantes más viejos en el barrio, nombres de las familias fundadoras, hitos importantes en la vida del sector. Es su carta de presentación, la oralidad hecha escritura. Hoy en día cuando en nuestro país, justamente por el procedimiento de regularización de la tenencia de la tierra en barrios urbanos, se solicita como requisito la carta del barrio, muchas comunidades populares comienzan a reconstruir sus orígenes. Paradójicamente por las condiciones del barrio Los Pinos (supuesta propiedad privada y por la inestabilidad de los terrenos), su historia relatada no ha repercutido ni en los organismos locales ni centrales para la obtención y mejoramiento de la comunidad. No obstante, en el campo de lo simbólico, la historia narrada ha sido una herramienta que les da sentido como grupo, los reafirma en no ser ocupantes de antigüedad reciente. Ellos han conquistado frágilmente, pero lo han hecho, un espacio en la ciudad...

\subsubsection{Los mecanismos inciertos de una relación vecinal}

A la pregunta ¿cómo es la relación entre los vecinos?, muchas respuestas afloran, hasta algunas contradictorias y divergentes. Para la señora C. es el egoísmo en el barrio lo que impera, no hay comunicación, la gente no colabora para el mejoramiento de las caminerías, para la limpieza del barrio. La señora L., sin embargo, comenta que se produce cierto 
Teresa Ontiveros Acosta

\begin{abstract}
LOS PINOS: VIVENCIA, DRAMAS SOCIALES Y CONSTRUCCIÓN DE SENTIDO. APROXIMACIÓN A UN TERRITORIO POPULAR URBANO DESDE LA ANTROPOLOGÍA DE LA EXPERIENCIA
\end{abstract}

grado de solidaridad vecinal, y ciertos vecinos gozan de un gran respeto (el señor G. dueño de la bodeguita, uno de nuestros entrevistados, el señor Ra. líder natural del barrio). Para la señora An., lo importante es saber convivir y respetar a los demás; el señor Ro. hace la diferencia entre la parte de arriba y la parte de abajo del sector A, todos coinciden en que sí se establece una diferencia entre el sector A y el sector B, hasta llegar a marcarse una distancia entre estos dos sectores. Los líderes comunitarios conversan con preocupación acerca de la poca participación de los habitantes en el mejoramiento del día a día de la comunidad, aunque existe la figura de la Asociación de Vecinos, ésta nunca (ni en la IV República, ni en el gobierno actual) ha recibido el apoyo de las autoridades locales. Hoy ni con la existencia de los Consejos Comunales, instancia local de participación popular y protagónica, esta comunidad ha podido conformarse en un Consejo, viendo así mermada la posibilidad de actuación ante los diferentes problemas que la aquejan.

Es interesante observar ante este panorama que las relaciones existentes en el barrio, además de la vecinal, están fuertemente impregnadas por el vínculo parental y de paisanaje, muy característico de los barrios populares venezolanos. Sólo después de realizadas las entrevistas, ya que éstas se hicieron a solicitud de la investigadora y de una que otra recomendación del líder natural del barrio, observamos la cadena que se teje entre varias de las familias del barrio: la señora An. es hermana de la señora E., quien es pareja de uno de los hijos del señor G.; el señor G. es el tío de la ex -pareja de la señora C., la ex pareja de la señora C. es primo del señor Ro., quien tiene como compadre a un vecino del barrio, y quien nos señala que aproximadamente 50 personas de las que conformaban el barrio hasta el año 2006 provenían de la misma región (El Empedrado, estado Lara) y aunque todavía quedan familias paisanas, por supuesto son menos. La señora A. fundadora del barrio, es prima hermana de la señora O., y uno de los hijos de la señora A., vive en vivienda aparte dentro del barrio; el señor Ra., líder del barrio tiene a una hija viviendo en el sector B; es decir, de los diez entrevistados, ocho tienen un vínculo familiar directo, de compadrazgo o de paisanaje.

¿Por qué entonces no se produce un lazo más estrecho y de impulso entre este grupo comunitario? La mayoría arguye que la sensación de no saber si se van o se quedan los ha llevado a una suerte de espera, sin poder actuar en cuanto a la mejora no sólo del barrio, sino de la misma vivienda. Pero, si esto es lo que dicen hoy las familias, retrospectivamente, encontramos por el mismo relato de los entrevistados que en momentos clave las familias 


\section{Artículos Arbitrados}

CUADERNO URBANO. Espacio, Cultura, Sociedad - VOL. 9 - № 9 (Octubre 2010) pp. 7-34. ISNN 1666-6186

han actuado en defensa de sus derechos. Si el intento de desalojo (año 2003) unió a las familias para su impedimento, la reubicación (avanzada en el año 2006) no sólo dividió a la comunidad entre los que se quedaron y los que se fueron, sino que aletargó a los que hoy permanecen en la comunidad. Hoy más que un miedo a la amenaza de desalojo, se advierte una impotencia colectiva, y sobre ésta dedicaremos algunas reflexiones.

\subsection{El drama social de Los Pinos: los que se quedaron}

4.4.1. Entre el desalojo, el riesgo geológico y la reubicación: crisis y fragmentación “... Bueno, eso fue un drama muy bravo lo que vivimos aquí, eso fue de repente que llegaron aquí, como a las diez de la mañana más o menos...” (Sr. G.), “... allá arriba se pusieron con los muchachitos tirados, había un sol bravo y los muchachos allí en el suelo" (esposa del Sr. G.), "llegó la policía a sacarnos..." (Sr. G.). Este relato hace referencia al intento de desalojo que sufrieron las familias de Los Pinos el $1^{\circ}$ de abril de 2003, pero habría que devolver muchas páginas para poder contextualizar y destejer lo que en palabras del mismo habitante considera el DRAMA vivido por la comunidad.

La historia de Los Pinos está marcada desde sus inicios por los intentos de desalojos. En el relato de la señora A., fundadora del barrio, desde mediados de los 80, desde su llegada, la Guardia Nacional intentó en varias oportunidades expulsar a las familias de los terrenos ocupados. Después de varios años de tensa calma, para finales de 1996 las familias del sector deciden organizarse en una asociación de vecinos. En 1997, las familias fueron citadas por la Guardia Nacional e interrogadas acerca de los documentos que poseían; desde ese momento, muchas familias procedieron a tramitar su título supletorio. En septiembre de 1998 la Empresa Mercantil Parque Cementerio La Puerta CA introduce una demanda, identificada en querella interdictal restitutoria de la posesión a 162 ciudadanos, habitantes de los barrios Los Pinos y La Planada, quienes fueron calificados de invasores y de haber ocupado la propiedad de esos terrenos entre noviembre de 1997 y agosto de 1998.

El proceso judicial se hace en reclamo de la posesión, ya que los demandantes señalan ser los dueños de los terrenos. El objetivo de este interdicto restitutorio era recuperar los terrenos para construir el Cementerio Parque de Sarteneja, éste debía producirse dentro del año en que ocurre la invasión. Introducido el documento en 1998, la fecha de invasión según la empresa sucede en noviembre de 1997. La ejecución de la orden se pospuso por varios años, alegando los demandantes las condiciones críticas que se vivían en el país y 
Teresa Ontiveros Acosta

\begin{abstract}
LOS PINOS: VIVENCIA, DRAMAS SOCIALES Y CONSTRUCCIÓN DE SENTIDO. APROXIMACIÓN A UN TERRITORIO POPULAR URBANO DESDE LA ANTROPOLOGÍA DE LA EXPERIENCIA
\end{abstract}

la situación de los tribunales. Pero en el año 1999 se inicia la fase de ruptura inminente para la comunidad: al ser considerada ésta "invasora", el Instituto de Vialidad y Transporte del Estado Miranda (INVITRAMI) construye un muro que separa por completo a las familias de la autopista. Esta fase la hemos denominado el mecanismo intimidatorio.

Luego de nueve largos meses y de una profunda crisis intensificada por las consecuencias que se derivaron del muro: inseguridad y muertes en el sector, los vecinos enviaron correspondencia al Presidente de la Cámara Municipal que manifestaba el malestar por dicha construcción. Hubo protestas y movilizaciones, a partir de las cuales las relaciones entre el barrio y las autoridades entran en un verdadero conflicto. Las familias colocan letreros en el muro en protesta por lo que consideran un acto humillante y exigiendo justicia trancan la autopista más de 300 personas y por estas acciones logran que el muro sea parcialmente derribado, permitiéndose así la entrada y salida a la zona. Ésta es la fase de reajuste al problema sufrido por la comunidad.

Después de esta etapa intimidatoria, los años subsiguientes (2000-2003) fueron años de intensos reclamos y solicitudes a las autoridades competentes para que dotaran a la comunidad de los servicios inexistentes (fase de reintegración), pero sin ninguna intervención que favoreciera a la colectividad. No obstante ello, el aprendizaje obtenido de acuerdo con las familias es que en la unión está la fuerza, establecer vínculos fuertes para resolver juntos los problemas que tanto los aquejan.

Pero el $1^{\circ}$ de abril de 2003 se lleva a cabo la ejecución judicial del Decreto Interdictal Restitutorio y con ello, el desalojo inminente, sigue siendo la condición de "invasores" el desencadenante de este nuevo drama social (fase de ruptura). La fase de crisis y su intensificación: el desplazamiento forzado que intentaron realizar a las familias de Los Pinos los representantes de la empresa junto con una comisión de la policía de Baruta y un transporte especial para sacar los enseres de los hogares, mientras las familias debían buscar su propio alojamiento. Mujeres, niños, hombres, todos tomaron el peaje, vecinos de los barrios cercanos acompañaron a Los Pinos en su protesta, la misma Guardia Nacional en ese momento evitó el desalojo de las familias. De nuevo hubo una aparente suspensión del conflicto (fase reparadora o de ajuste) y las familias debieron comparecer ante los tribunales. La situación no está superada (fase de reintegración) y las familias siguen a merced del desalojo. 


\section{Artículos Arbitrados}

CUADERNO URBANO. Espacio, Cultura, Sociedad - VOL. 9 - № 9 (Octubre 2010) pp. 7-34. ISNN 1666-6186

Pero a estos procesos de quiebre social, crisis y su intensificación, reajustes y reintegración, producto todas estas fases de la condición de ocupación indebida de los terrenos, se le agrega otro aspecto mucho más complejo y es la comprensión de habitar en un terreno inestable. Especialmente en los períodos de lluvia, las familias viven en estado de alerta, aunque subrayaremos, el riesgo natural es menos temido que el riesgo social (violencia e inseguridad).

Tres años después de este intento de desalojo, las familias de los Pinos se enfrentan a otro acontecimiento: la reubicación. Según relatos de las familias, muchos vieron con júbilo esta posibilidad de ser reubicadas, aunque admiten querer su barrio, ya sabían que después de una resistencia sostenida a través de los años, demostrada a través de muchas correspondencias a los organismos regionales y nacionales, a personajes políticos de peso en el país, visitas a la prensa, a televisoras regionales, públicas y privadas, para mostrar las grandes carencias del barrio, éste nunca contó con políticas de mejoramiento integral.

En el año 2006, el máximo mandatario regional, Diosdado Cabello, procedió a través del Instituto de Vivienda del estado Miranda a reubicar a las familias del sector Los Pinos. Algunas de ellas a través del Plan VIII pudieron comprar sus casas y salir del barrio; otro grupo pequeño (cinco familias aproximadamente) fue reubicado en la urbanización Jardines de Betania y otro grupo (aproximadamente veinticinco familias) trasladado a la urbanización Ciudad Betania. En total, aproximadamente 40 familias del barrio salieron del sector.

El resto de las familias (unas 40) permaneció en el barrio, con la promesa de ser trasladadas a los quince días. Para evitar intentos de ocupación, las autoridades procedieron a destruir las viviendas y dejar el barrio en condiciones más precarias que las existentes. Estas familias, a pocos meses de la reubicación de la mitad de su población, comienzan a exigir una explicación de su futuro inmediato: ise van o se quedan? Sin respuesta comienza un proceso de deterioro no sólo del barrio, sino psicológico para las familias. A la agravante de la falta de servicios se le suma la imposibilidad de mejoramiento tanto del barrio como de sus casas; ¿cómo destinar lo poco que se tiene, lo que se gana, si luego más adelante se pierde todo lo invertido? Se va alimentando entre estas familias una suerte de desesperanza y parálisis colectiva por no saber qué hacer, cómo actuar. Se desencadena un nuevo drama social, y esta vez produciéndose una crisis del ser colectivo. 
Teresa Ontiveros Acosta

\begin{abstract}
LOS PINOS: VIVENCIA, DRAMAS SOCIALES Y CONSTRUCCIÓN DE SENTIDO. APROXIMACIÓN A UN TERRITORIO POPULAR URBANO DESDE LA ANTROPOLOGÍA DE LA EXPERIENCIA
\end{abstract}

Esta crisis se intensifica en la medida en que van conociendo que ni el poder local (hoy en día en manos de la denominada oposición al gobierno, y según explicación, por no contar con los recursos ni con la injerencia que tenía la gobernación en el tema de la vivienda), ni el Ministerio del Poder Popular para las Obras Públicas y Vivienda (Mopvi) dan respuestas inmediata a su situación.

A tres años de espera para este grupo que permanece en Los Pinos, comienza un nuevo malestar colectivo y es el referido a los intentos de reocupación del barrio por personas ajenas a la comunidad. Le temen al repoblamiento; en este proceso de narración y reflexividad, las familias se sienten vulneradas en su condición de venezolanos y venezolanas que merecen una vivienda y un barrio dignos, se sienten marginados, y de haberse considerado posesionarios de una vivienda y un territorio, la vulnerabilidad los ha llevado a sentirse en condición de arrimados en su propio barrio, y esta figura en las representaciones bien arraigadas entre los venezolanos es lo menos deseado, ya que ello denota los rasgos más intensos de la dependencia con relación a terceros.

Las imágenes del pasado que se evocan, los eventos revividos y el pasado articulado al presente nos muestran una experiencia de vida social cargada de significaciones, en la cual la realidad del barrio ha estado marcada por los dramas sociales, y la fragmentación y la ambivalencia entre el permanecer o partir han intensificado la crisis de sentido. La conciencia compartida nos muestra vínculos muy frágiles dentro del colectivo, éstos se reactivan ciertamente en los momentos más liminares de la vida social, pero mientras tanto, la identidad del grupo sostenida a través de la resistencia y por la conquista del espacio urbano se ve desgastada por los intensos grados de exclusión.

La fase de reintegración en un proceso de drama social y en nuestro caso de estudio nos muestra con crudeza un proceso franco de fragmentación.

4.5. La paradoja de la inclusión: los que se fueron

Se podría entender como un logro el que un grupo de familias mejoren su calidad de vida después de décadas de falta de servicios, equipamientos, etc. en su sector; desde una Antropología del Espacio, podemos entender el arraigo que se produce entre los sujetos sociales y su entorno de vida, pero, en el caso que nos ocupa, constatar que estamos ante 


\section{Artículos Arbitrados}

CUADERNO URBANO. Espacio, Cultura, Sociedad - VOL. 9 - № 9 (Octubre 2010) pp. 734. ISNN 1666-6186

una realidad extremadamente vulnerada a partir de las tendencias constantes al desalojo y los riesgos geológicos inminentes, el considerar su reubicación puede ser positivo en la medida en que ello repercutiría en la calidad de vida y en dar respuestas a la deuda social contraída con estas familias en particular. Es comprensible, entonces, compartir el alivio colectivo que cuentan las familias les produjo la oportunidad de la partida, sólo que no todas las familias fueron reubicadas al mismo tiempo. Aproximadamente $25 \mathrm{fa}$ milias de las 40 reubicadas fueron trasladadas al Desarrollo Urbanístico Ciudad Betania, emplazado en Ocumare del Tuy, Municipio Lander, del estado bolivariano de Miranda (imágenes 12,13).

Si bien las familias beneficiarias comentan cierto grado de confort de estos apartamentos, comienza a circular dos, tres años después de la partida la tragedia y el horror de vivir en Ciudad Betania. Fue una constante en todas las entrevistas el temor de la posibilidad de ser reubicadas en este lugar. Quiere decir que las vivencias de los que se fueron han llegado a Los Pinos; varias familias incluso han conversado mucho con el líder natural y con otros miembros de la comunidad para regresar al barrio. Las personas que trabajaban en el peaje y recibieron vivienda todos los días se trasladan a éste a cumplir con sus labores.

En vista de estas opiniones y como parte de entender la investigación como un proceso, entrevistamos a dos jefas y un jefe de familia trasladados a Ciudad Betania. El señor $\mathrm{CH}$. cuenta que tiene su bodeguita, y si bien no le ha ido mal, constantemente tiene que negociar con los malandros de la zona. La señora F. comenta lo dantesco de la situación,
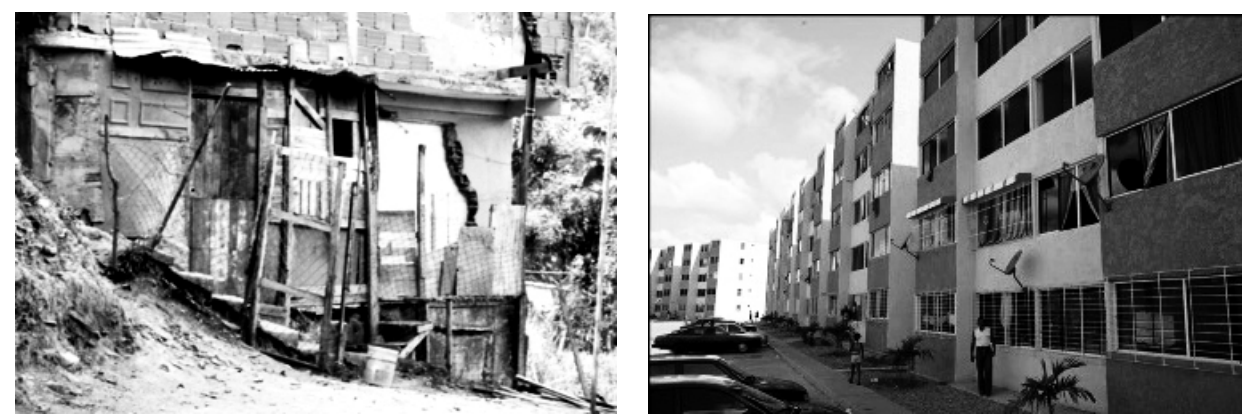

12 y 13: Ciudad Betania. Ocumare del Tuy, Miranda. Foto tomada del blog Realidad Alternativa. 17 de abril de 2008 
Teresa Ontiveros Acosta

\begin{abstract}
LOS PINOS: VIVENCIA, DRAMAS SOCIALES Y CONSTRUCCIÓN DE SENTIDO. APROXIMACIÓN A UN TERRITORIO POPULAR URBANO DESDE LA ANTROPOLOGÍA DE LA EXPERIENCIA
\end{abstract}

lo más grave, nos dice, es que si se produce un enfrentamiento entre malandros, los familiares de éstos tienen que salir de la zona, ya que sus vidas están sentenciadas. La señora G. fue la entrevistada más sentida; con lágrimas nos decía lo siguiente: “... como el cambio era así, un ranchito a un apartamento, pero cuando uno está allá es que ve de todo, de todo, el agua le llega a una cierta hora...Yo me fui de aquí con los ojos cerrados, porque la que me dijo a mí que eso allá era mejor que aquí, hay seguridad, hay de todo, pero no hay guardia, no hay nada, allá está, sálvense quien pueda... y desde adentro uno ve todo para fuera, horrible, y yo aquí dormía con la puerta abierta”.

Estos relatos nos advierten cómo más allá de la "buena voluntad" de los organismos y dependencias vinculadas con el área de la vivienda, hay aspectos de la vida social que no se contemplan en las reubicaciones. No se trata de trasladar a las personas y "depositarlas" en las viviendas, éstas vienen con historias, vivencias, redes de relaciones, intercambios de costumbres familiares/vecinales; es perceptible que estos grupos vivan procesos de recomposición de su memoria. En un nuevo contexto espacial nuevas heterogeneidades se presentan y el cruce de memorias debe dar como resultado el encuentro y crecimiento colectivo. El espíritu de la convivencia, la tolerancia, el respeto hacia el otro deben tomarse en cuenta y ser trabajados colectivamente cuando se produce este entrecruzamiento de grupos venidos de muchos lugares, si no, las consecuencias pueden ser nefastas, ya que la relación se establece sobre la base de la tensión y no del vínculo.

Esta situación nos lleva a advertir que los mecanismos de la inclusión deben ser multidimensionales/estructurales. Una vivienda digna significa igualmente trabajo, educación, salud, recreación, transporte dignos. Apropiación de los espacios públicos, fortalecimiento del principio de ciudadanía, intensificación del vínculo entre los que comparten un espacio, redimensión de la relación identidad/alteridad, afianzamiento de la historia local, arraigo y sentido de pertenencia: estos dispositivos no han logrado articularse entre los que se fueron.

Esta reflexión surgida de la experiencia de vida de la señora A resume su expresión y comprensión del fenómeno, en un proceso de verdadero diálogo entre los pobladores y los técnicos planificadores. Advertencias como éstas deben ser procesadas colectivamente y aprender de ellas: "Bueno la única manera sería que, asimismo como vivimos aquí lo único que yo puedo aspirar de esa experiencia que vivamos en otro sitio que cuando nos den 


\section{Artículos Arbitrados}

CUADERNO URBANO. Espacio, Cultura, Sociedad - VOL. 9 - № 9 (Octubre 2010) pp. 734. ISNN 1666-6186

la vivienda si nos las piensan dar pues... lo que yo estoy pidiendo para mí, para ellos mismos también la comunidad y que seamos en verdad unidos en verdad no sólo aquí, sino cuando salgamos de aquí también sigamos unidos iverdad?, porque dicen que en la unión está la fuerza, y bueno, debemos ser unidos aquí y donde vayamos, y pedirle que todos nos ubiquen juntos, para que ellos entiendan de que es mejor vivir en comunidad..."(Sra. A. fundadora del barrio).

\section{CONCLUSIONES}

Experiencia de vida social y construcción de sentido: estar y no estar en el mundo (de lo urbano)

Los territorios populares urbanos (barrios autoproducidos) albergan en la actualidad al $56 \%$ del total de la población que vive en la ciudad. En palabras de la arquitecta-urbanista TEOLINDA BOLÍVAR, constituyen el fragmento predominante de la metrópoli capital (BoLívar, 2010, snp). Los barrios han constituido y constituyen una forma particular de hacer ciudad. Estos asentamientos y sus pobladores forman parte del tejido urbano y han contribuido a modelar la "memoria espacial urbana" de los últimos cincuenta años. Una historia y memoria de estos territorios populares urbanos darían cuenta de la homogeneidad heterogénea (ONTIVERos, 2002), no sólo referida a la construcción física, sino también a lo relacionado con los aspectos culturales.

En estos últimos diez años los barrios han vivido cambios considerables. Se vienen llevando a cabo intentos de regularización de la tenencia de la tierra, implementándose algunos programas de vivienda (sustitución de ranchos por casas, intentos de habilitación de barrios bajo la figura de transformación de los barrios urbanos), se han insertado tímidamente en el sistema de salud a partir de la misión Barrio Adentro, se ha incorporado la figura de los consejos comunales, a través de los cuales se aspira a la participación y protagonismo de los ciudadanos (en todos los niveles y grupos sociales); a través de diferentes misiones (Robinsón, Ribas, Milagro, Madres del Barrio, Sonrisa, Negra Hipólita, etc.) se hace un esfuerzo denodado por incorporar a los barrios en la estructura urbana. A pesar de esta lucha, muchos barrios continúan en la precariedad y sin recibir lo que por derecho les asiste: una calidad de vida digna.

El barrio Los Pinos, apenas un pequeño territorio de la Gran Caracas, nos ha develado que en sus 23 años de existencia su condición de segregado, excluido, se ha mantenido en el 
Teresa Ontiveros Acosta

\begin{abstract}
LOS PINOS: VIVENCIA, DRAMAS SOCIALES Y CONSTRUCCIÓN DE SENTIDO. APROXIMACIÓN A UN TERRITORIO POPULAR URBANO DESDE LA ANTROPOLOGÍA DE LA EXPERIENCIA
\end{abstract}

tiempo y en el espacio. Muchas de las familias del barrio siguen cifrando sus esperanzas en el proceso que se vive en el país; sin embargo, muestran cómo el barrio es un ejemplo de las contradicciones que se producen entre el poder local y el nacional. La Alcaldía (regida por la "oposición") no ha velado ni buscado soluciones conjuntas, consensuadas con la comunidad; los programas de vivienda, en manos del gobierno, tampoco han logrado dar respuestas a los conflictos y dramas que viene acumulando este grupo social. Ciertamente, como bien lo explica una habitante, se sienten viviendo en el "limbo" (situación liminar) y sin ninguna posibilidad inmediata de tener en claro cuál es la salida.

Las experiencias de vida acumuladas por este grupo y evidenciadas a través de la circulación de las vivencias nos muestran una historia local sellada por un sentido de pertenencia ambivalente (irse o quedarse), por una identidad de la amenaza (desalojo e inestabilidad geológica), un vínculo social frágil, el cual se activa en los momentos de intensificación de las crisis y conflictos sociales. Es dable entender en esta circunstancia que los rituales de interacción también sean frágiles, la vida individual y social ha estado abocada al intento de solución de las necesidades más abrumadoras. El sentido se construye a propósito de una experiencia de la sobrevivencia.

Los grandes acontecimientos que se producen en ciertos ciclos de nuestra vida cotidiana: las fiestas, las recreaciones colectivas, las prácticas lúdicas, el uso del espacio público, están negados para esta comunidad. Por ello, podemos entender cómo el orden social y la solidaridad interna se tambalean en el contexto de Los Pinos. Es así como en parte la negación del tiempo de lo sagrado, parafraseando al antropólogo Manuel Delgado, hace que se escuche un colosal e insoportable murmullo, "... el ruido enloquecedor de un tiempo al que le habría sido extirpado el sentido" (DeLGADO, 2004: 79). Pero, ante estos dramas sociales que pudimos reconstruir a través de las narrativas locales, hay un dispositivo que articula, que hace que esas voces se vuelvan una y es el orgullo de mostrar e insistir en la tranquilidad y seguridad (social) que vive el barrio. De hecho, este aspecto constituyó para los habitantes un punto de comparación con el resto de la ciudad y de muchos de los barrios, una suerte de oasis ante los altos índices de violencia en otros barrios de la ciudad, pero se rompe la calma al pensar en la reubicación.

Hemos intentado interpretar (como antropóloga) la dinámica socio-cultural que se vive en Los Pinos, hemos querido abordar el discurso implícito de esta comunidad, con base en 


\section{Artículos Arbitrados}

CUADERNO URBANO. Espacio, Cultura, Sociedad - VOL. 9 - № 9 (Octubre 2010) pp. 734. ISNN 1666-6186

la experiencia de vida social. Aunque estuvimos allí compartiendo a través del diálogo las vivencias del colectivo, sentimos que el estar allí no basta. El consejo del señor Ra. líder natural del barrio es contundente: “... si usted quiere saber cómo es la situación aquí en Los Pinos, usted tendría que venirse a vivir, siquiera tres o cuatro meses [continuos] aquí en Los Pinos, para que usted pueda ver la experiencia de lo que se vive aquí...". Sin embargo, lo que vimos, sentimos, vivenciamos, nos enseñó a reconocer que a través de las experiencias compartidas (circulación de las mismas), podemos estar en capacidad también de reconocer las experiencias de los otros, de allí recurrir a la comprensión como elemento articulador del intercambio entre los grupos, aspecto fundamental en la fase de reintegración y del cambio social.

Las mismas voces de la comunidad que individualmente en su proceso de reflexividad dan cuenta de este quiebre colectivo servirán de estímulo para reavivar la necesidad de restablecer los vínculos sinérgicos para buscar las soluciones una vez más como comunidad. Nuestra tarea, desde un encuentro entre etnografía y experiencia es intentar circular estas vivencias y sus expresiones individuales, para reconstruir un nos-otros, servir de puente para el reconocimiento público de unos y otros y desde allí reclamar, negociar, las salidas más beneficiosas para el colectivo de Los Pinos.

\section{BIBLIOGRAFÍA}

AGUIRRE CAUHÉ, Silvia (1997). "Entrevistas y cuestionarios". En: AGUIRRE BAZTÁN, Ángel, Ed., Etnografía. Metodología cualitativa en la investigación cultural. Alfaomega Grupo Editor, SA de C.V, México.

AUGÉ, Marc (2004) ¿Por quévivimos? Por una antropología de los fines. Gedisa Editorial, Barcelona.

BARBIER, René (1997). "El educador como 'passeur de sens". En: Congreso internacional ¿Cuál universidad para mañana? Haciauna evolución transdiciplinaria de la Universidad. Locarno, Suiza.

BOLÍVAR, Teolinda (2010) "Editorial (I)". Centro Ciudades de la Gente. Escuela de Arquitectura Carlos Raúl Villanueva. Facultad de Arquitectura y Urbanismo. Universidad Central de Venezuela. Centro de Investigación Barrios Autoproducidos. http:// centrociudadesdelagente.blogspot.com/ 17 de febrero de 2010.

CORRALES DÍAZ, Carlos (1997) “La constitución o construcción del sentido”. htpp:// 
Teresa Ontiveros Acosta

\begin{abstract}
LOS PINOS: VIVENCIA, DRAMAS SOCIALES Y CONSTRUCCIÓN DE SENTIDO. APROXIMACIÓN A UN TERRITORIO POPULAR URBANO DESDE LA ANTROPOLOGÍA DE LA EXPERIENCIA
\end{abstract}

iteso.mx/carlosc/pagina/documento/sentido3.htm. Revisado el 28-05-2006.

DAWSEY John (2005). "Víctor Turner e antropología da experiencia". En: Cadernos de Campo. Revista dos alunos de pós-graduaçao em antropologia social DA USP. ISSN $0104-$ 5679. Alo 14-2005.

DELGADO, Manuel (2004). "Tiempo e identidad. La representación festiva de la comunidad y sus ritmos". Universidad de Barcelona. Insititut Català d'Antropologiia. Baldiri Reixac. s/n. 08028, Barcelona.

DÍAZ CRUZ, Rodrigo (1997). "La vivencia en circulación. Una introducción a la antropología de la experiencia”. En: Alteridades 7 (13), México.

GEERTZ, Clifford, (2005) La interpretación de las culturas. Gedisa Editorial, decimotercera reimpresión, Barcelona.

JOSEPH, Isaac (1988) El transeúnte y el espacio urbano. Sobre la dispersión y el espacio público. Editorial Gedisa, Argentina.

ONTIVEROS, Teresa (1985) "Marín. La mémoire collective d'un barrio populaire à Caracas". Tesis de Doctorado de Tercer Ciclo. París, Universidad París VII (Jussieu). Tutor académico, Jean Duvignaud.

ONTIVEROS, Teresa (1996) "Memoria Colectiva e Historias de Vida. Teoría y praxis para una aproximación a los territorios populares contemporáneos (barrio). En: NAVARRETE, Rodrigo (compilador). La mirada penetrante: reflexiones y prácticas del discurso antropológico. Fondo Editorial Tropykos; Comisión de Estudios de Postgrado, Facultad de Ciencias Económicas y Sociales, Universidad Central de Venezuela.

ONTIVEROS, Teresa (2000) Memoria espacial y hábitat popular urbano. Doce experiencias familiares en torno a la casa de barrio. Caracas, Facultad de Ciencias Económicas y Sociales-Fondo Editorial Trópykos.

ONTIVEROS, Teresa (2002). "Caracas y su gente... la de los barrios". En: Revista Venezolana de Economía y Ciencias Sociales. Tema central: Caracas, sus procesos y su gente (coordinado por CASTILLO, Ocarina. Vol. 8, №3. Facultad de Ciencias Económicas y Sociales. Universidad Central de Venezuela.

ONTIVEROS, Teresa (2010). "Experiencia de vida social y construcción de sentido en un territorio popular urbano. Caso Los Pinos. Hoyo de la Puerta. Baruta. Área Metropolitana de Caracas". Informe Final. Investigación financiada por el Consejo de Desarrollo Científico y Humanístico (CDCH). Universidad Central de Venezuela. Caracas.

ONTIVEROS, Teresa y Julio De FREITAS (1996). "Repensando el barrio: papel del antropólogo en la rehabilitación de los espacios autoproducidos". En: BOLÍVAR, Teolinda 


\section{Artículos Arbitrados}

CUADERNO URBANO. Espacio, Cultura, Sociedad - VOL. 9 - № 9 (Octubre 2010) pp. 734. ISNN 1666-6186

y Josefina BALDÓ (compiladoras). La cuestión de los barrios. Perspectiva actual. Monte Ávila Editores Latinoamericana, Fundación Polar, Universidad Central de Venezuela, Caracas, Venezuela.

ONTIVEROS, Teresa y Armando GUTIÉRREZ (2004). "Esto es lo único que tengo". Amenazas de desplazamientos forzados de población y mecanismos de resistencia. Caso barrio Los Pinos, Hoyo de la Puerta, Municipio Baruta. Área Metropolitana de Caracas. Oficina Regional de la Coalición Internacional para el Hábitat (HIC-A.L), México, Grupo de Investigación La producción de los Barrios Urbanos de la Facultad de Arquitectura y Urbanismo y Escuela de Antropología, de la Facultad de Ciencias Económicas y Sociales, Universidad Central de Venezuela, Caracas.

RUANO, Leticia (2000). "De la construcción de los otros por nosotros a la construcción del nos-otros”. En: Metodología Cualitativa. Educar. Revista de Educación/Nueva Época Núm. 12/Enero-Marzo. Guadalajara, Jalisco CP.

SCHECHNER, Richard (2000) Performance: teoría y prácticas interculturales. Libro del Rojas, Buenos Aires.

TURNER, Victor (1974) Dramas, fields and metaphors. Ithaca. Cornell University Press.

TURNER, Victor (1982a). "Images of Anti-Temporality: An Essay in the Anthropology of Experience". The Harvard Theological Review, Vol. 75, № 2.

TURNER, Victor (1982b) From ritual to theater. Nueva Cork. Paj Publications.

TURNER, Victor (1990) La selva de los símbolos. Siglo XXI, Madrid. 